\title{
Doctors urged to improve Aboriginal child health
}

$\mathrm{D}$ octors and other health care professionals must use all the tools at their disposal to fight poverty, counteract colonization and create an environment in which indigenous children thrive, Canadian broadcaster and rap/hip-hop artist Wab Kinew told the Sixth International Meeting on Child Indigenous Health.

"I love this country and I am fully cognizant of the opportunities that I have been afforded living here," said Kinew, the keynote speaker at the conference in Ottawa Mar. 20-22. "However, I know that it can do better. I know that it can do much better."

Speakers from Canada, the United States and Australia presented research and statistical snapshots that made it clear indigenous children in all three countries have dramatically poorer health outcomes than their peers. From the emergence of new and potentially deadly infections like Haemophilus influenzae type b (Hib) and the resurgence of diseases long eradicated in other parts of the developed world, to staggeringly higher rates of suicide, injury and homicide, Type II diabetes and food insecurity, indigenous children are at high risk.

"We still have residual challenges as it relates to some of our health indicators and health determinants. These are really truly unjust and we can't accept the status quo," said Dr. James Irvine, medical health officer for the Northern Saskatchewan Population Health Unit in La Ronge, Saskatchewan.

Infant mortality is 2.5 times greater among Inuit children in Nunavut than the rest of the population, and up to four times greater among Inuit children in Nunavik, in northern Quebec, said Irvine. If they are off-reserve, $35 \%$ of Aboriginal children under six live in poverty, compared to $18 \%$ of nonAboriginal children. Aboriginal children make up $48 \%$ of all children 14 and under in foster care in Canada, a social determinant that has an impact on their health for years to come, he added.

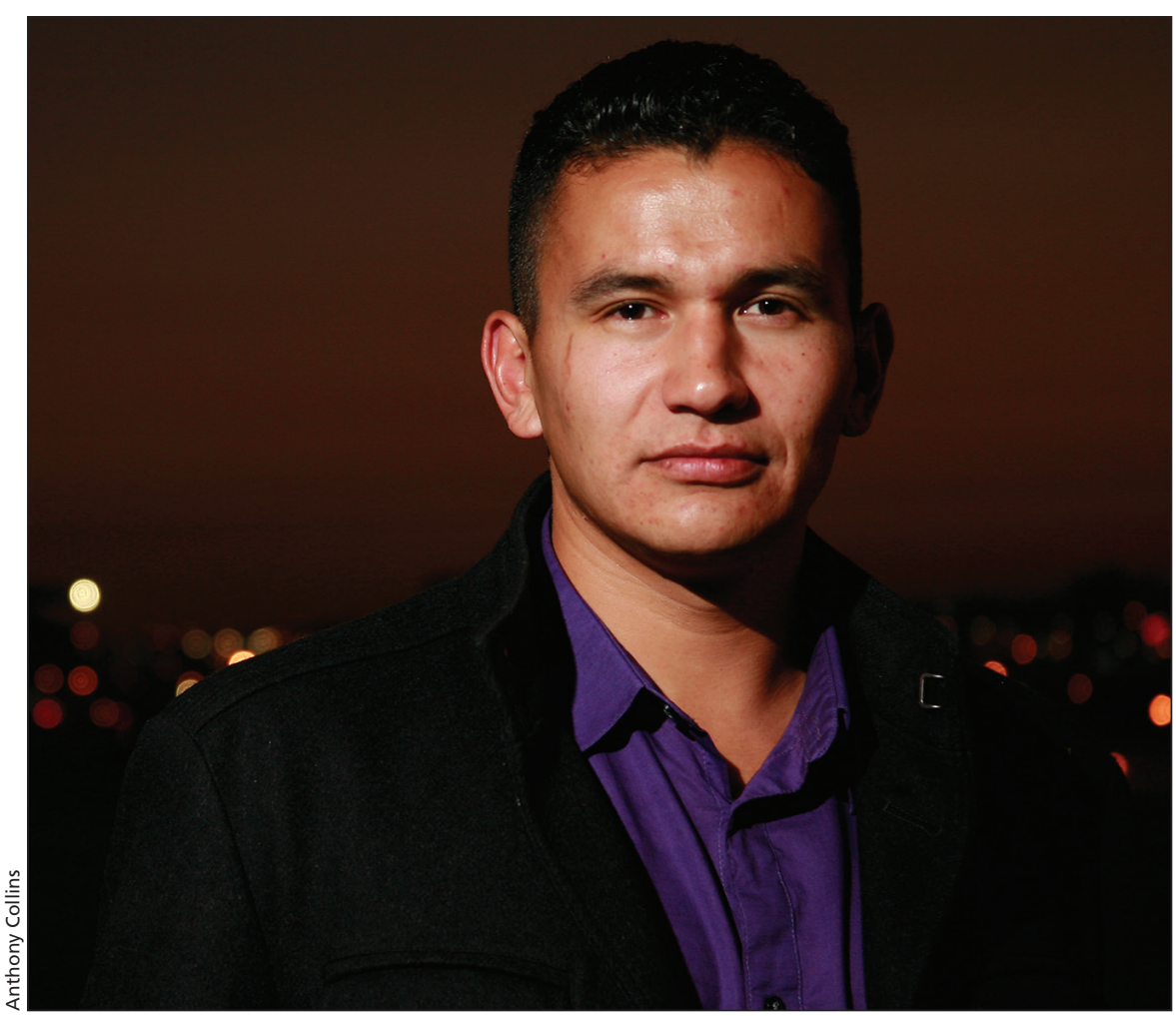

"We're still debating whether First Nations kids should have equal access to health care," said Canadian broadcaster Wab Kinew.

In the US, infant mortality rates are roughly comparable between white and Native children, said Dr. Steve Holve, national chief clinical consultant in pediatrics for the US Indian Health Service. But native children are 2.5 times more likely than children in the general population to die between one month and a year, and have twice the risk of sudden infant death syndrome, three times the risk of death from injuries and five times the risk of death from flu and pneumonia, he added.

"Native children are born healthy, but they often go home to a risky and risk-filled environment," said Holve, who is a pediatrician on the Navajo Nation. By age five, Native American/ Alaskan Native children are at 3.5 times greater risk of being murdered than white children, he added. Native teenagers are at six times the risk of death by suicide compared to other American teens.

Combining the benefits of Western medicine and traditional knowledge would help to improve the lives of Canada's most vulnerable citizens, Kinew said, emphasizing the strength he draws from the traditional teachings and healing practices of the Midewiwin, an Ojibwe medicine society. "Everything is medicine that's one of the things we need to bear in mind as we do work in our communities."

But protecting Aboriginal, Inuit and Métis languages and culture is not enough to save the next generation, which is the largest-growing demographic in Canadian society, said Kinew, who is the acting associate vice-president of Indigenous Affairs at the University of Winnipeg. Even young people immersed in their culture and deeply committed to participating in traditional ceremonies have succumbed to despair and taken their own lives, he said.

"I know people who were in the Midewiwin and knew the songs, and yet they took their own lives. I know 
people who were Sundancers, I know people who were pipe carriers, and they still committed suicide," he said. "I know tons of people who follow the Red Road, and yet are diabetic. So culture and language are hugely important, but they're not a silver bullet, they're not a panacea."

Kinew called it "super frustrating" to live in a country where outdated policies and attitudes co-exist with rising numbers of smart, well-educated young Aboriginal professionals grounded in their languages and culture. "Apparently in this country, we're still debating whether First Nations kids deserve equal access to education. We're still debating whether First Nations kids should have equal access to health care. We're still debating whether or not the Charter of Rights and Freedoms applies on reserve. Should indigenous women be four times more likely to be murdered? That's a legitimate debate in this country, apparently." - Laura Eggertson, Ottawa, Ont.

CMAJ 2015. DOI:10.1503/cmaj.109-5032 